\title{
(t)
}

\section{FETICHISMO E AUTONOMIZAÇÃO DAS FORMAS SOCIAIS NA CRÍTICA DA ECONOMIA POLÍTICA DE MARX}

\author{
FETICHISM AND AUTONOMIZATION OF SOCIAL FORMS IN THE MARX'S \\ CRITIQUE OF POLYTICAL ECONOMY
}

\section{Gerson dos Santos Silva ${ }^{1}$}

\section{RESUMO}

Diante da atual encruzilhada histórica onde a crise estrutural do capital sinaliza seus limites lógicos e históricos, o presente trabalho objetiva lançar contributos para uma crítica radical da sociedade burguesa. Nesse sentido, propomos uma leitura do livro I de O Capital analisando as categorias mercadoria, valor e trabalho em seu duplo aspecto, desvelando seu caráter fetichista e historicamente determinado e expondo o desenvolvimento lógico-histórico de autonomização destas categorias. Por conseguinte, analisamos o desenvolvimento desse processo de autonomização categorial e determinação formal na figura do dinheiro e do capital. Com isso, objetivamos colaborar com a consolidação das bases para uma crítica radical de uma sociedade que exige que as relações sociais ocorram como relações entre coisas e apresenta um metabolismo social invertido, na medida em que trabalho e dinheiro como formas sociais autonomizadas - se tornam um fim em si, exigindo que a sociabilidade seja determinada pela finalidade tautológica de valorização do valor.

Palavras-chave: Crítica da Economia Política. Fetichismo. Autonomização das formas sociais.

1 Bacharel em Serviço Social pela Universidade Federal Fluminense (UFF). Tem realizado estudos e pesquisas em torno da crítica da economia política de Marx buscando apreender o conjunto de mediações e determinações essenciais que conformam a atual estrutura de reprodução do capital a partir do vínculo constitutivo entre teoria do valor, crise estrutural e processo de financeirização-ficcionalização do capital. 


\section{temporollis}

\section{ABSTRACT}

Given the current historical crossroads where the structural crisis of capital signals its logical and historical limitations, the present study aims to launch contributions to a radical critique of bourgeois society. In this sense, we propose a reading of Book I of Capital analyzing the merchandise categories, value and work in its dual aspect, unveiling its fetishistic character and historically determined and exposing the logical historical development of autonomy of these categories. Therefore we analyze the development of this categorical independence process and formal determination in the figure of money and capital. With this we aim to collaborate with the consolidation of the foundations for a radical critique of a society that requires social relationships occur as relations between things and presents an inverted social metabolism, as work and money - as autonomous social forms - become an end itself, demanding that the entire social life is determined by the purpose tautological (and misguided) appreciation of value.

Keywords: Critique of Politycal Economy. Fetichism. Autonomization of social forms.

Submissão - 08/09/2016

Aceite $-13 / 01 / 2017$

\section{Introdução}

Ao retomar a exposição lógico-histórica de Marx no livro I de $O$ Capital objetivamos colaborar com a consolidação das bases para uma crítica radical da sociedade burguesa, analisando suas formas sociais específicas (mercadoria, trabalho em seu duplo aspecto, valor, dinheiro, capital) em seu desenvolvimento lógico e histórico. A apreensão do desenvolvimento lógico e histórico dessas categorias e de seu processo imanente de autonomização, nos permite afirmar que a sociedade burguesa conserva em sua estrutura um tipo específico de determinação formal que lança imperativos concretos na sociabilidade capitalista a partir de um processo social de abstração (das qualidades sensíveis da mercadoria, do caráter útil dos trabalhos nela representados, do dinheiro, do valor e do capital) especificamente capitalista.

Na forma expositiva da crítica da economia política de Marx, a exposição dos desdobramentos lógicos abstratos se realiza em conexão com os desdobramentos do conteúdo material histórico, por isso, afirmamos que na crítica de Marx encontramos uma exposição lógico-histórica, na medida em que a exposição lógica e formal está intimamente ligada ao conteúdo material historicamente determinado. 


\section{tempordils}

No presente trabalho nos propomos a uma leitura do livro I de O Capital analisando, no primeiro momento, as categorias mercadoria, valor e trabalho em seu duplo aspecto, desvelando seu caráter fetichista e historicamente determinado e expondo o desenvolvimento lógico-histórico de autonomização destas categorias. Esse processo se expressa historicamente como movimento de autonomização de relações reais coisificadas, configurando um primeiro patamar de autonomização categorial. No segundo momento analisamos o desenvolvimento desse processo na figura do dinheiro e do capital, onde o valor se desprende de sua necessidade direta de representação nos valores de uso das mercadorias e se encarna no dinheiro, adquirindo um nível superior de autonomização. Com isso, exige não somente que as relações sociais ocorram como relações entre coisas, mas inverte o metabolismo social, de modo que o trabalho e dinheiro como formas sociais autonomizadas - se tornam um fim em si. Partindo desta perspectiva chegamos à categoria de capital como relação automediada do valor consigo mesmo (na dimensão lógica) e como relação autonomizada de consumo exorbitante de força de trabalho em condições de exploração (na dimensão sócio-histórica), desfechando assim as bases do processo de autonomização das categorias sociais capitalistas. Acreditamos que esta perspectiva de análise nos permite lançar contributos para uma teoria crítica da modernidade capitalista, contribuindo para uma crítica radical da sociedade burguesa imprescindível para compreender a atual formatação do capitalismo contemporâneo e a urgente necessidade de sua supressão histórica.

\section{Autonomização e determinação formal - mercadoria, valor e tra- balho}

A análise da mercadoria como ponto de partida revela uma contradição imanente, esta contradição estruturante entre abstrato e concreto deflagrada na forma-mercadoria se defronta com seus próprios limites lógico-históricos. No movimento automediado do valor estes limites internos encontram sua resolução temporária apenas na reposição desta contradição estruturante em um nível superior, esta saída temporária repõe a necessidade de outra saída sucessiva, esta reposição de formas conflitantes regressa em níveis avançados de determinação formal abstrata sobre o conteúdo concreto-sensível, constituindo assim o impulso do ininterrupto movimento de fuga para frente do capital. O ponto fundamental de nosso trabalho se assenta 


\section{temporalis}

na análise do capital como "sujeito automático", um "sujeito automático" (MARX, 2011) e automediado que se desenvolve nas múltiplas formas de manifestação fenomenal que adquire no percurso de sua exposição.

No corpo da mercadoria estão conservados os traços gerais de toda sociabilidade capitalista, em sua lógica imanente encontramos a particularidade das relações sociais especificamente capitalistas. A mercadoria é aqui apreendida como forma historicamente determinada de uma sociedade que exige que as relações sociais entre indivíduos ocorram como relação (reificada) entre coisas, a produção compulsória destas coisas torna-se ao eixo central das relações sociais. Por isso, a mercadoria será nosso ponto de partida.

A mercadoria é a forma de aparência da riqueza na sociedade capitalista, partindo de sua singularidade "[...] a mercadoria é, antes de tudo, um objeto externo, uma coisa que, por meio de suas propriedades, satisfaz necessidades humanas de um tipo qualquer" (MARX, 2013, p. 113). A mercadoria é um objeto produzido pelo trabalho humano, um objeto exterior a seu produtor e vocacionado primordialmente para a venda na instância funcional do mercado. As utilidades das mercadorias são condicionadas em sua própria dimensão corpórea: o valor de uso, a natureza imprescindível do objeto na forma de riqueza material mediante um conjunto de qualidades sensíveis.

Especificamente na sociedade burguesa este universo material dos valores de uso constitui o suporte veicular para o valor de troca, na medida em que nesta sociedade as mercadorias não são apenas objetos dotados de utilidade, mas são, primordialmente, objetos vocacionados à troca por outras mercadorias. Portanto, o valor de uso não pode ser apreendido apenas como um utensílio material vinculado às necessidades humanas, na sociedade capitalista o valor de uso aparece determinado pela necessidade de materialidade do valor, sua funcionalidade social encontra sentido primordialmente no âmbito das equivalências entre mercadorias.

O valor de troca "[...] aparece inicialmente como relação quantitativa, a proporção na qual valores de uso de um tipo são trocados por valores de uso de outro tipo, uma relação que se altera constantemente no tempo e no espaço" (MARX, 2013, p. 114). Nisto identificamos a natureza dúplice que se instaura no corpo da mercadoria, sua contradição latente entre valor de uso (riqueza material) e valor de 


\section{tempordilis}

troca (forma de manifestação da riqueza abstrata).

Os valores de troca se realizam na possibilidade de objetos distintos - estranhos entre si e divorciados daqueles que os produziram - se tornarem passíveis de troca a partir de um princípio social de redutibilidade equivalente. Esta proporção na qual valores de uso distintos se tornam equivalentes necessita obedecer a critérios específicos e socialmente válidos, na ciranda das trocas as mercadorias "[...] têm de ser valores de troca permutáveis entre si ou valores de troca de mesma grandeza" (MARX, 2013, p. 115). Para que se efetue uma relação de troca entre mercadorias é necessário que ocorra uma redução prática de todo lastro material envolvido, neste momento a mercadoria é um não valor de uso para seu possuidor, se alienando do mesmo. Esta relação nos mostra que algo de mesma grandeza abstrata se interpôs entre as duas mercadorias. Desta relação de enfrentamento entre mercadorias os valores de troca vigentes expressam algo igual: o valor.

Na relação de troca, em detrimento à dimensão concreta e sensível da mercadoria, a mercadoria se torna um corpo de valor abstrato, uma "coisa sensível suprassensível”, vazia de conteúdo, despovoada de qualquer átomo de valor de uso. Com isto, podemos apreender que a oposição interior encerrada na mercadoria revela um terceiro elemento em comum: o valor das mercadorias. Com a negação dos valores de uso como característica central das relações de troca resta nas mercadorias apenas uma propriedade em comum, a de serem mercadorias oriundas de processos de consumo de força de trabalho em condições de exploração, ou seja, a qualidade em comum das mercadorias reside no fato de serem todas elas fruto do trabalho humano.

No curso das transformações das mercadorias inseridas na troca, a imposição formal assentada sobre o conteúdo sensível das mercadorias anula as formas corpóreas destas - não se trata mais de bolsas, armas ou calças jeans - bem como, de igual forma, esta mesma abstração que apaga as qualidades concretas da mercadoria faz desaparecer o caráter útil das atividades representadas nestas.

Com o caráter útil dos produtos do trabalho desaparece o caráter útil dos trabalhos neles representado e, portanto, também as diferentes formas concretas desses trabalhos, que não mais se distinguem uns dos outros, sendo todos reduzidos a trabalho humano igual, a tra- 


\section{temporollis}

balho humano abstrato. (MARX, 2013, p. 116).

Em continuidade a exposição da categoria trabalho abstrato Marx desvela a categoria valor já pressuposta no jogo dialético entre valor de uso e valor de troca. O valor de troca veio a lume como forma de expressão de um conteúdo diferente de si: o valor. Portanto, o valor de troca (aparência) é a forma como o valor (essência) aparece. $O$ valor surge como o algo em comum capaz de tornar todas as mercadorias mensuráveis, por isso, a relação entre duas mercadorias é a relação direta entre uma determinação formal (o valor) e um suporte objetivo (o valor de uso). O valor pode ser descrito como uma abstração formal, uma forma determinada socialmente que necessita do lastro material como seu suporte. Portanto, não se trata de apreender o valor como uma redução abstrata apenas pensada, mas sim, como uma abstração que se faz real, justamente porque a universalidade formal do valor encontra alicerce no horizonte material da sociedade capitalista.

$\mathrm{Na}$ categoria valor podemos ter acesso ao que, antes, estava pressuposto por trás da relação de troca: a substância socialmente constituída, o trabalho reduzido a mero dispêndio de músculos, nervos e cérebro. Marx afirma que a grandeza de valor é determinada pelo tempo de trabalho e quando aqui falamos de trabalho as equivalências temporais são as únicas possíveis. Uma hora despendida para a fabricação de um tênis é, a rigor, uma hora de trabalho. A objetividade do valor das mercadorias desdobra-se a partir de sua redução em unidades abstratas de tempo, aqui Marx chega ao importante conceito de "tempo de trabalho socialmente necessário":

\footnotetext{
Tempo de trabalho socialmente necessário é aquele requerido para produzir um valor de uso qualquer sob as condições normais para uma dada sociedade e com grau social médio de destreza e intensidade de trabalho. [...] O valor de uma mercadoria está para o valor de qualquer outra mercadoria assim como o tempo de trabalho necessário para a produção de uma está para o tempo de trabalho necessário para a produção de outra. (MARX, 2013, p. 117).
}

A partir do conceito de "tempo de trabalho socialmente necessário" podemos vislumbrar os processos de troca da sociedade capitalista por outro prisma, deixando a aparência da "coisa" podemos apreender que, quando trocamos mercadorias distintas (quando participamos dos atos rotineiros de compra e venda de mercadorias) es- 


\section{tempordilis}

tamos, de fato, operacionando a troca de unidades abstratas de tempo de trabalho cristalizadas nos corpos das mercadorias. Com base nesta perspectiva podemos apreender que o valor é uma forma de riqueza estabelecida e regulada pelo "tempo de trabalho socialmente necessário", uma mediação social que exige que as relações sociais se realizem como relação entre coisas.

Marx desenvolve a análise do duplo caráter do trabalho partindo de seu caráter útil, como trabalho produtor de valores de uso. A enorme coleção de mercadorias da sociedade burguesa é, de fato, uma coleção de objetos concretos dotados de certo caráter sensível; estes objetos úteis são oriundos de diferentes tipos de processos de trabalho, estes processos são realizados na forma de "[...] trabalhos privados, separados e mutuamente independentes uns dos outros" (MARX, 2013, p. 120). Na própria exposição do conceito de "tempo de trabalho socialmente necessário" vemos que duas determinações indissociáveis se articularam: as dimensões concreta e abstrata. Vejamos que, para se produzir um valor de uso é necessário que certa concreticidade de atividades úteis sejam realizadas, esta dimensão concreta do "tempo de trabalho socialmente necessário" é apresentada como trabalho concreto (ou útil); entretanto, nesta mesma atividade útil imbrica-se uma dimensão abstrata (o trabalho abstrato) que se expressa no valor da mercadoria, podemos então caracterizar o trabalho como trabalho abstrato-concreto. Por isso, a racionalidade quantitativa determinada por um critério temporal e indiferente contida no conceito de "tempo de trabalho socialmente necessário" se torna objetivada não apenas na forma concreta de trabalhos úteis, mas, ao mesmo tempo constituindo formas de dispêndio compulsório de força de trabalho homogênea.

Abstraindo-se da determinidade da atividade produtiva
e, portanto, do caráter útil dos trabalhos, resta o fato
de que ela é um dispêndio produtivo de força humana
de trabalho [...]. Assim como os valores de uso casaco e
linho constituem nexos de atividades produtivas orien-
tadas a um fim e realizadas com o tecido e fio, ao passo
que os valores casaco e linho são, ao contrário, simples
geleia de trabalho, também os trabalhos contidos ness-
es valores não valem pela relação produtiva que guar-
dam com o tecido e o fio, mas tão somente como dispên-
dio de força humana de trabalho (MARX, 2013, p. 121-22).

Este dispêndio de força de trabalho não se separa em momen- 


\section{temporalis}

tos de concretude e momentos abstratos: há um único trabalho dotado de duplo caráter que se ancora na finalidade de produzir valor, esta contradição imanente ao desenvolvimento da mercadoria e do trabalho é constantemente tensionada pela força objetiva do valor em sua finalidade única de autovalorização. Trabalho concreto-abstrato e processo de trabalho-valorização são, em si, unidades contraditórias determinadas pela vocação suprema de realizar a finalidade ontológica do capital: sua reprodução ampliada. Esta contradição originária presente em toda estrutura do capital se expressa na mercadoria e no trabalho na forma de uma concretude fraturada, dada a imposição da forma valor em sua necessidade de se materializar, constituindo uma concretude em conflito permanente com sua oposição abstrata.

\section{Autonomização e fetichismo - mercadoria, formas de valor, di- nheiro e capital}

$\mathrm{Na}$ análise das mercadorias podemos desvelar o valor que nelas se esconde, partindo da forma de manifestação (aparência) ao fundamento da forma (essência). Nesse ponto Marx retoma a análise do valor de troca para edificar a gênese lógica do dinheiro, expondo em níveis de complexidade contínuos a análise lógica das diferentes formas de valor que precedem a forma-dinheiro; nesta rota expositiva Marx parte da relação simples entre duas mercadorias, desdobrando desta forma simples a forma total e universal para, enfim, chegar à forma-dinheiro.

Na forma simples de valor a objetividade de valor aparece na relação entre duas mercadorias, a equação $x$ mercadorias $A=y$ mercadorias $B$ pressupõe uma igualdade de essências entre mercadorias distintas ( $A$ e $B$ ) que, sendo postas em equivalência, manifestam dois polos de expressão do valor: a forma de valor relativa e a forma equivalente. Na relação simples entre os polos $A$ (forma relativa) e $B$ (forma equivalente), Marx analisa a expressão de valor que aparece nesta relação: a expressão de valor de $A$ esta representada no corpo de $B$, do ponto de vista da mercadoria $A$ a mercadoria $B$ torna-se sua medida de valor, se $y$ mercadorias $B$ equivalem a $x$ mercadorias $A$ algo de mesma grandeza está sendo representado no valor de uso de $B$. Neste sentido, $B$ figura como forma equivalente de $A$. A relação entre as formas relativa e equivalente presente na forma de valor simples externaliza a contradição imanente da forma-mercadoria, sua oposi- 


\section{tempordis}

ção interna se externaliza, pois, a forma relativa e a equivalente "[...] são momentos inseparáveis, inter-relacionados e que se determinam reciprocamente, mas ao mesmo tempo, constituem extremos mutuamente excludentes, isto é, polos da mesma expressão de valor." (MARX, 2013, p. 126).

As mercadorias A e B são portadoras de valor, como valores $A$ e $B$ não são mais do que unidades de trabalho humano, reduzidas à abstração (real) do valor, quando inseridas em uma relação de valor a mercadoria $B$, na forma de equivalente, vale como forma de existência do valor de $A$. Neste ato, aparentemente idílico, de pôr $A$ e $B$ em uma relação de equivalência o trabalho contido em $A$ é equiparado ao trabalho contido em $B$ sendo ambos reduzidos à trabalho humano abstrato, a determinação formal do valor usurpou o espaço de toda distinção sensível da mercadoria e dos trabalhos nela representados.

Na relação onde a mercadoria $A$ expressa seu valor no corpo da mercadoria $B, A$ confere em $B$ uma forma específica de valor, a forma equivalente. No interior desta relação de valor apenas $A$ encontrou seu valor de troca (que está revelado em $B$ ), como polo equivalente de $A$ não há qualquer determinação quantitativa de valor em $B$. Por isso, 2 mercadorias $B$ expressam a grandeza de valor de 20 mercadorias $A$, mas, 2 mercadorias $B$ jamais expressará sua própria grandeza de valor em relação consigo mesma, pois, nenhuma mercadoria pode existir como seu próprio equivalente, ao contrário, é necessário fazer da corporeidade de outra mercadoria a sua forma de valor. Deste quiproquó próprio ao mundo das mercadorias Marx nos aponta a primeira peculiaridade da forma de equivalente: vemos que $A$ encontrou sua forma de existência (sua "sociabilidade" no mundo das mercadorias) em B. Com isso, "[...] o valor de uso se torna a forma de manifestação de seu contrário, do valor. A forma natural da mercadoria [B] torna-se forma de valor [de A]." (MARX, 2013, p. 133). Esta relação de inversão da forma nos revela o caráter enigmático da forma de valor equivalente; sendo uma relação ancorada em algo puramente social (o valor), esta aparece de forma natural e corriqueira, o fato do valor vir a lume a partir do corpo de outra mercadoria parece ser algo acidental, um valor intrínseco existente como uma propriedade natural das mercadorias, como se a vocação originária de $B$ fosse unicamente ser material de expressão do valor de $A$.

No equivalente $B$ o valor da mercadoria $A$ surge na figura de seu oposto (o próprio corpo de $B$ ). Nesse momento, a mercadoria $B$ 


\section{temporalis}

dissimula o valor aparentando ser ele mesmo valor, um equivalente que possui por natureza a forma de valor. Toda complexidade envolvida no interior da relação que faz de $B$ o equivalente de $A$ é encoberta no próprio corpo de $B$. Vemos aqui os primeiros argumentos de Marx que nos conduzirão pari passu ao fetichismo da mercadoria.

$\mathrm{Na}$ análise do conjunto da forma de valor simples vemos que a natureza dúplice da mercadoria aparece na forma de manifestação de seu valor, necessariamente, em outro corpo de mercadoria. Uma forma de manifestação distinta de sua própria matéria e que necessita se afirmar na relação de troca com outra mercadoria. Nesta relação fetichista as inversões reais que se impõem (a saber, o valor de uso, o trabalho concreto e privado sendo convertidos em seu oposto: valor, trabalho abstrato e imediatamente social) são obscurecidas.

A forma de valor total (ou desdobrada) se caracteriza pela possibilidade aberta da mercadoria $A$ se enfrentar com múltiplas mercadorias emergindo assim um conjunto de formas simples de valor. Nesse sentido, a forma de valor da mercadoria A transpõe os limites encontrados na forma anterior (a forma simples que a permitia apenas se relacionar com a mercadoria $B$ ). Agora o valor de $A$ pode ser representado em quantidades crescentes de mercadorias, sua "cidadania" foi conquistada no mundo das mercadorias. Nessa relação a grandeza de valor de $A$ permanece, as variedades de valor de troca que se apresentam ( $y$ mercadoria $B$, ou $x$ mercadoria $C$, etc.) não modificam em nada a mercadoria $A$; com isso apreendemos que o componente regulador das relações de troca é intrínseco à forma mercadoria, pois, reside em seu próprio imperativo interno: a força objetiva e indiferente de seu valor. "O valor das mercadorias é indiferente a forma específica do valor de uso [...] torna-se evidente que não é a troca que regula a grandeza de valor da mercadoria, mas, inversamente, é a grandeza de valor da mercadoria que regula as relações de troca." (MARX, 2013, p. 139).

A forma total, embora tenha desenvolvido um caráter universal (na medida em que abarca uma infinitude de mercadorias) se defronta com a variabilidade contínua das formas de expressão do valor, seu principal entrave reside onde apenas o valor de uma mercadoria $(A)$ é expresso, as demais mercadorias servem de material para expressão do valor de $A$, mas não o seu contrário. Não ocorre na forma total a fixação de uma forma particular de expressão de valor que venha considerar o colorido mosaico de mercadorias por ela posto, nesta 
confusão generalizada, as expressões de valor desconexas e diversificadas que emergem não permite que no polo equivalente ocupe uma única mercadoria capaz de conservar a estabilidade necessária de um equivalente universal. Diante disto, vemos que a aparente resolução da insuficiência da forma simples impôs um novo limite lógico na forma total, a "manifestação unitária" que vimos sendo representada no corpo da mercadoria $B$ (na forma simples) se dilui em diversas possibilidades (na forma total). A superação dos limites encontrados na forma total se deflagra justamente na inversão de sua própria forma, onde $A$ torna-se equivalente geral das demais mercadorias $(B, C, D$, etc.), a partir desta inversão encontramos a forma de valor universal.

$\mathrm{Na}$ forma de valor universal os limites internos das formas de valor precedentes são removidos, a superação destes limites internos é descrita por Marx de forma dialética, nos permitindo compreender os complexos caminhos do ser-valor na estrutura lógica da seção primeira de O Capital. A forma universal engloba a síntese da forma simples e total, nesta forma as mercadorias encontram sua expressão de valor de modo simples e unitário. "Sua forma de valor é simples e comum a todas, e, por conseguinte, universal." (MARX, 2013, p. 141); recai sobre a singularidade concreta de uma única mercadoria o estatuto de universalidade, uma forma simples que encontra significado na totalidade da sociabilidade das mercadorias. No mundo das mercadorias a forma de valor universal expressa o aspecto social próprio dos produtos do trabalho nas sociedades onde impera o modo de produção capitalista: a substância social formadora de valor, o trabalho abstrato. "A forma de valor universal, que representa os produtos do trabalho como meras geleias de trabalho humano, mostra, por meio de sua própria estrutura, que ela é a expressão social do mundo das mercadorias." (MARX, 2013, p. 143).

Das rotas enigmáticas da forma de valor simples e total chegamos à forma de valor universal, onde, a partir desta, encontramos a ofuscante forma-dinheiro. Entre a enorme coleção de mercadorias da sociedade burguesa uma mercadoria específica conquistou historicamente o lugar privilegiado de equivalente universal, o ouro. Assim sendo, se na forma de valor universal substituirmos a mercadoria $A$ por ouro, teremos a forma-dinheiro. Segundo Marx, o processo de gênese da forma-dinheiro - embora seja apresentado com certo relevo sobre sua estrutura lógica - é um processo perpassado por determinações históricas, onde "[...] por meio do hábito social, a forma da permutabilidade direta e geral ou a forma de equivalente universal 


\section{temporalis}

amalgamou-se definitivamente à forma natural específica da mercadoria ouro." (MARX, 2013, p. 145).

Nos desdobramentos expositivos da seção primeira de $\mathrm{O}$ Capital, Marx desvela as especificidades fundamentais de "[...] uma formação social em que o processo de produção domina os homens, e não os homens o processo de produção." (MARX, 2013, p. 156). Nesse mundo invertido as relações sociais são ocultadas e aparecem necessariamente como relações entre coisas, como produtos do trabalho que dominam seus próprios criadores.

"Uma mercadoria aparenta ser, à primeira vista, uma coisa óbvia, trivial. Sua análise resulta em que ela é uma coisa muito intricada, plena de sutilezas metafísicas e melindres teológicos." (MARX, 2013, p. 146). Se partirmos de sua aparência imediata vemos que em seu corpo não existe mistério algum, revirando-a de ponta-cabeça vemos que suas utilidades, sua cor, cheiro, tamanho, preço, composição química, em nada disso há inquietações. Desta forma, de onde viria este caráter enigmático das mercadorias?

Segundo Marx o caráter enigmático da mercadoria surge de sua própria estrutura. Podemos seguir suas pegadas partindo do desenvolvimento das formas de valor, onde a oposição interna da mercadoria como "forma elementar" se desenvolveu como oposição externalizada, como relação de equivalência entre mercadorias distintas. Retomando as análises anteriores das formas de valor, vemos que este caráter fetichista esteve pressuposto no "caráter enigmático da forma de valor equivalente".

Como a forma de valor relativa de uma mercadoria, por exemplo, [a mercadoria A] o linho, expressa sua qualidade de ter valor como algo totalmente diferente de seu corpo e de suas propriedades, como algo igual a [mercadoria B] um casaco, essa mesma expressão esconde em si uma relação social. O oposto ocorre com a forma de equivalente, que consiste precisamente no fato de que um corpo de mercadoria, como o casaco, essa coisa imediatamente dada, expressa valor e, assim, possui, por natureza, forma de valor. (MARX, 2013, p. 134).

Selecionamos esta passagem acima como ponto de partida para apreensão do fetichismo da mercadoria, pois, a propriedade de possuir valor de uma mercadoria aparece como algo natural. Nesse sentido, a materialidade socialmente constituída da forma de valor 


\section{tempordilis}

equivalente (dinheiro) surge como algo imanente, à semelhança de uma "lei natural" incontestável, tanto na forma de valor simples, quanto na forma universal. Por conseguinte, nesta relação social dominante onde os produtos do trabalho assumem a condição de coisas de valor, um conjunto de inversões estruturantes se estabelece, tais inversões configuram um segundo aspecto no desenvolvimento do fetichismo da mercadoria: o valor de uso se tornou forma de manifestação de seu contrário, o valor; o trabalho concreto e privado tornouse expressão de seu oposto, trabalho abstrato imediatamente social. Portanto, agora, a estrutura contraditória da mercadoria desenvolvida na forma de valor regressa em estado latente na análise do caráter fetichista da mercadoria, neste complexo conjunto de inversões vemos que:

O caráter misterioso da forma mercadoria consiste, portanto, simplesmente no fato de que ela reflete aos homens os caracteres sociais de seu próprio trabalho como caracteres objetivos dos próprios produtos do trabalho, como propriedades sociais que são naturais a essas coisas e, por isso, reflete também a relação social dos produtores com o trabalho total como uma relação social entre os objetos, existente à margem dos produtores [...]. [Portanto, esta relação] É apenas uma relação social determinada entre os próprios homens que aqui assume, para eles, a forma fantasmagórica de uma relação entre coisas. (MARX, 2013, p. 147).

A partir desta afirmação vemos que, ao ser lançado em igualdade de essências, todo conjunto de trabalhos concretos torna-se a substância formadora do valor, seu aspecto útil e sensível torna-se secundário, sendo reduzido a trabalho indiferenciado. As relações sociais nas quais se realizam as inversões postuladas acima se encontram subsumidas na figura do valor, tornam-se relações obnubiladas, imperceptíveis feito um "ponto cego", aparecendo apenas como relações entre os produtos do trabalho; estes produtos do trabalho aparecem como coisas dotadas de um "valor intrínseco", seu valor surge como uma "propriedade natural" que empresta significado e inteligibilidade às relações de compra e venda de mercadorias (relações estas que estruturam todo conjunto da vida social capitalista).

A potencialidade inebriante das mercadorias faz com que estas se apresentem como produtos dotados de "fôlegos de vida", a ciranda ininterrupta das trocas entre mercadorias nos é dada como movimento - sutilmente apreendido como movimento imanente à pró- 


\section{temporollis}

pria mercadoria - que alcança plena autonomia, uma força exterior e objetiva que organiza a vida social, configurando uma sociabilidade estranha que, no entanto, se naturaliza. Neste sentido, 2 camisetas = $R \$ 200,00$ é a forma de manifestação de um conjunto de relações sociais que apenas conseguem se manifestar pela mediação das coisas.

Como os produtores só travam contato social mediante a troca de seus produtos do trabalho, os caracteres especificamente sociais de seus trabalhos privados aparecem apenas no âmbito dessa troca. [...] As relações sociais entre seus trabalhos privados aparecem como aquilo que elas são, isto é, não como relações diretamente sociais entre pessoas em seus próprios trabalhos, mas como relações reificadas entre pessoas e relações sociais entre coisas (MARX, 2013, p. 148).

Sendo a sociedade capitalista organizada fundamentalmente a partir da onipresença das mercadorias, as relações de troca tornamse o núcleo socializador da totalidade da vida. Portanto, fora dos circuitos de troca que nos cercam torna-se obstruída a possibilidade de sociabilidade.

Para Marx (2013) a primeira atribuição da mercadoria dinheiro é proporcionar ao mundo das mercadorias a materialidade específica de sua expressão de valor. No interior do conjunto de inversões da forma valor, a mercadoria-equivalente retoma as contradições estruturantes da mercadoria e torna-se forma de expressão de seu contrário (uma dimensão essencialmente abstrata). O caráter enigmático da mercadoria-dinheiro reside justamente nesta forma socialmente válida de representação do valor, pois, oculta em seu corpo a relação social que constitui o valor (o puro dispêndio de força de trabalho em condições de exploração), ou seja, a substância do valor aparece como um elemento orgânico do dinheiro, uma qualidade natural e imanente capaz de relacionar qualitativa e quantitativamente qualquer coisa útil. Marx desvela essa aparente qualidade natural do dinheiro afirmando que não é o poder enigmático do dinheiro que torna as mercadorias comensuráveis entre si, a possibilidade de qualquer critério de mensurabilidade advém daquilo que toda mercadoria possui em comum: o fato de ser trabalho morto, objetos que corporificam força psicofísica e se alienam de seu produtor. Sendo as mercadorias corpos que conservam consigo determinada grandeza da substância do valor (ou seja, unidades de tempo de trabalho socialmente necessário) elas se tornam comensuráveis por si próprias, o dinheiro 


\section{tempordilis}

é apenas a "aparência da coisa", a representação de uma medida conjunta de valor.

Neste sentido, o dinheiro como "manifestação imanente de valor" é capaz de mensurar a quantidade de valor de uma mercadoria como quantidades de si próprio. Partindo disso, na expressão uma calça jeans $=R \$ 95,00$, podemos apreender que o dinheiro (como medida de valor da calça jeans) nos mostra que o valor em seu movimento automediado alcançou um segundo patamar de autonomização: na figura do dinheiro, como quantidades de um valor de uso específico (ouro, cédulas de papel, etc.) o valor se autonomiza se externalizando como equivalente universal perante o mundo das mercadorias e, neste mesmo movimento, escondendo sua verdadeira condição de relação social de exploração.

À medida que a mercadoria é um corpo de valor, algo material submetido à imposição da forma, suas contradições se conservam em estado latente, a resolução parcial das contradições localizadas no desenvolvimento dialético das formas de valor à gênese lógica do dinheiro apenas impulsionam as contradições de base para um novo estágio mais avançado, na relação entre mercadoria e mercadoriadinheiro. Com a mercadoria-dinheiro como meio de circulação podemos falar de uma contradição imanente que, ao invés de se resolver por completo, se expande, sobre tudo porque o ato de compra e venda de mercadorias se torna o processo social dominante da sociedade capitalista.

Neste momento Marx retoma o processo de troca e a importância de se apreender o aspecto formal que está oculto aos agentes do processo de troca, pois, "[...] se nos concentrarmos exclusivamente nesse momento material, na troca de mercadoria por ouro, ignoramos justamente aquilo que se deve ver, a saber, o que se passa com a forma." (MARX, 2013, p. 178-9). O status de mediação equivalente universal do dinheiro faz com que recaia sobre sua matéria (ouro, prata, cédulas de papel) uma existência puramente formal e fantasmagórica, um valor autonomizado que se desgarrou do valor de uso, o caráter natural (valor de uso) do ouro torna-se diluído pelo caráter social existente na forma-dinheiro.

A partir disto, podemos apreender a duplicação processual da mercadoria em mercadoria e mercadoria-dinheiro. A contradição interna da mercadoria é a reposta em nível superior como unidade 


\section{temporalis}

contraditória externa, ou seja, a circulação de mercadorias ao mesmo tempo em que se externaliza em duplo caráter (na relação entre mercadoria e dinheiro) se externaliza potencializando as contradições de base da mercadoria, propiciando assim o movimento de autonomização da forma-valor na figura do dinheiro.

Sendo o valor a forma específica de riqueza abstrata da sociedade capitalista e o trabalho abstrato sua substância, vemos que, nesta sociedade, não existe nenhuma outra forma de enriquecimento que não seja pelo trabalho (em sua dupla determinação). Essa imposição formal capitalista determina que os indivíduos expressem sua existência pautada em abstrações sociais. $\mathrm{O}$ "comportamento meramente atomístico" dos indivíduos faz com que estes expressem sua existência social unicamente como vendedores e compradores de mercadorias.

A relação de troca exige que cada indivíduo só se aproprie da mercadoria (produto do trabalho de outros) à medida que aliena sua própria mercadoria (seu próprio produto). A mercadoria originária do possuidor de dinheiro mudou de forma, despojando-se de sua forma de valor de uso, o dinheiro aparece como forma objetivada do puro dispêndio de trabalho humano e, neste momento, o possuidor da mercadoria camiseta (forma restrita de riqueza material) se coloca diante do possuidor de dinheiro (forma de expressão da riqueza abstrato-universal da sociedade burguesa). Eis a contradição estruturante da mercadoria expressa na forma de existência dos indivíduos: compra (compradores) e venda (vendedores) como atos (de indivíduos) separados e mutuamente excludentes.

A sociedade burguesa é caracterizada por uma forma específica de "interdependência social" (impessoal) e de "dependência coisal" (reificada) mediadas pelo trabalho. Esta rede de conexão social reificada é realizada pelos indivíduos, mas, se desenvolve para além do controle destes. Aqui vemos que nossos possuidores de mercadorias descobriram que a mesma estrutura social que lhes possibilita a pretensa independência pessoal, é a estrutura que lhes impõe a dependência "coisal" do mercado e social do trabalho, ou seja, a mesma estrutura social que possibilita ao produtor de mercadorias uma experiência social aparentemente independente da sociedade é, contraditoriamente, a estrutura social que o torna dependente dos outros indivíduos que possuem as mercadorias dinheiro e força de trabalho. Em suma, o produtor privado dessas coisas acha sua inde- 
pendência no interior de uma estrutura social de dependência reificada. Nos Grundrisse Marx expõe o caráter autônomo dessa estrutura social reificada:

O caráter social da atividade, assim como a forma social do produto e a participação do indivíduo na produção, aparece aqui diante dos indivíduos como algo estranho, como coisa; não como sua conduta recíproca, mas como sua subordinação a relações que existem independentemente deles e que nascem do entrechoque de indivíduos indiferentes entre si. A troca universal de atividades e produtos, que deveio condição vital para todo indivíduo singular, sua conexão recíproca, aparece para eles mesmos como algo estranho, autônomo, como uma coisa. No valor de troca, a conexão social entre as pessoas é transformada em um comportamento social das coisas; o poder pessoal, em poder coisificado. (MARX, 2011, p. 105; grifo nosso).

Na metamorfose das mercadorias (mudança de forma das mercadorias) vimos que o ato de venda e compra de mercadorias torna-se o momento essencial da circulação, a mercadoria é trocada por dinheiro e o dinheiro é trocado por outra mercadoria. Por isso, os atos de compra e venda de mercadorias surgem como atos apartados no tempo e no espaço, atos mutuamente indiferentes. As trocas entre mercadorias constituem o metabolismo social, se tornando essencialmente trocas por dinheiro construindo uma dependência universal da forma social dinheiro. O dinheiro se eleva socialmente como finalidade da produção (produzir para vender, ter mais dinheiro para ter mais dinheiro ad infinitum), não existindo apenas como mediação para troca de mercadorias, mas, para, além disso, se elevando como forma social autônoma que conduz o estranho processo social da modernidade capitalista:

O que aparecia originariamente como meio para o fomento da produção converte-se em uma relação estranha aos produtores. Na mesma proporção com que os produtores se tornam dependentes da troca, a troca parece tornar-se independente deles e parece crescer o abismo entre o produto como produto e o produto como valor de troca. (MARX, 2011, p. 95).

Em O capital Marx ainda afirma que essa transformação da forma das mercadorias, o desenvolvimento ampliado do processo de vender (M-D) para comprar (D-M), afasta-se de ser um meio social e torna-se fim em si: "[...] 


\section{temporolis}

a mercadoria é vendida não para comprar mercadoria, mas, para substituir a forma-mercadoria pela forma-dinheiro. De simples meio do metabolismo essa mudança de forma converte-se em fim de si mesma." (MARX, 2013, p. 204). O movimento de separação entre compra e venda indica a possibilidade destes movimentos não se tornarem unos, vejamos:

O produtor de vinagre necessita de que a cozinheira (para temperar pratos) ou o jovem militante (para aliviar o efeito da fumaça de bombas lacrimogêneas) comprem vinagre, como possuidores de dinheiro a cozinheira e o militante irão possibilitar ao produtor de vinagre saciar sua necessidade de ouvir um bom disco de Miles Davis. O produtor dos discos de igual forma necessita vender discos para comprar cigarros. Se o produtor de vinagre não realizar sua venda não poderá consumir o Kind of blue de Miles Davis, agudizando assim a crise de abstinência do produtor de discos havido por cigarros e, por tabela, o produtor de cigarros não poderá comprar sua cartela mensal de adesivos de nicotina. Podemos ver, neste exemplo, que a separação dos momentos de venda e compra implica a possibilidade de sua não realização completa - o que para Marx configura a possibilidade da crise - e com isso a necessidade de se acumular dinheiro torna-se latente, pois, nem toda compra é precedida por uma venda e com isso o dinheiro passa de meio a fim em si.

Podemos apreender que a mercadoria, como mediação social historicamente determinada, por um lado, cria o produtor privado e "independente" e, por outro, conforma a sociabilidade capitalista como um processo social alienado e independente dos próprios indivíduos, constituindo assim um sistema de dependência "coisal" que insere os indivíduos em relações sociais fetichistas determinadas por uma finalidade tautológica: a valorização do valor.

$\mathrm{Na}$ estrutura do processo de constituição do capital podemos apreender que a relação entre o dinheiro (como primeira forma de manifestação do capital) e o capital formam uma relação entre aparência e essência da forma social capitalista, bem como, a circulação de mercadorias torna-se suplantada na circulação do dinheiro como capital. O que podemos extrair deste processo de constituição do capital é a formação de um "sujeito automático", uma forma específica de relação social dotada de certa autonomia na medida em que se expressa nos produtos do trabalho humano pela mediação social do trabalho e, portanto, submetendo os próprios indivíduos a esta lógica. 


\section{tempordis}

O movimento autonomizado de circulação do valor (no dinheiro) aparece como D-M-D, conversão de dinheiro em mercadoria e sua reconversão em dinheiro (comprar para vender). Esta circulação de dinheiro transforma-se em circulação do dinheiro como capital, pois, segundo sua determinação já é capital. Para Marx, "[...] a circulação do dinheiro como capital é, ao contrário, um fim em si mesmo, pois a valorização do valor existe apenas no interior desse movimento sempre renovado." (MARX, 2013, p. 228). Portanto, mercadoria e dinheiro ao se tornarem formas de expressão do capital modificam a forma, de M-D-M (dinheiro como mediação do processo) para D-M-D (dinheiro como finalidade). Esta finalidade tautológica implica a necessidade do dinheiro (D) inicial reaparecer ao final do processo como mais-dinheiro (D'), ou seja, mais-valor, e este mais-valor será convertido em mais mercadorias para se reconverter em mais-valor ad eternum. Cabe destacar que este movimento tautológico não configura o crescimento de riqueza, mas, crescimento de valor (riqueza abstrata especificamente capitalista), o que configura uma estranha relação do valor consigo mesmo. Este valor que se valoriza é o valor que se torna capital. "O valor originalmente adiantado não se limita, assim, a conservar-se na circulação, mas nela modifica sua grandeza de valor, acrescenta a essa grandeza um mais-valor ou se valoriza. E esse movimento o transforma em capital." (MARX, 2013, p. 227).

A relação posta na fórmula D-M-D implica sua realização de forma ininterrupta, na qual ' $D$ ' precisa se transformar incessantemente em $M-D, M-D$, etc. Quando colocamos a circulação de mercadoria ( $M$ D-M) em relação a formula contínua de circulação do dinheiro como capital (D-M-D) vemos que na circulação das mercadorias existe um objetivo extrínseco, a realização de valores de uso. Entretanto, na circulação do dinheiro como capital conforma-se um sistema fechado e impessoal com a finalidade intrínseca de valorização do valor - estranhamente o valor em relação consigo mesmo torna-se um meio para um fim em si próprio! O capital para Marx é valor que se valoriza, com isso vemos que em nossas análises passadas da forma-mercadoria e da forma-dinheiro a categoria capital já estava (implicitamente) sendo reconstruída, uma categoria que ao mesmo tempo em que se desenvolve consegue se dissimular em suas próprias formas de manifestação. Neste movimento expositivo focado em uma crítica do valor, vemos que:

O valor passa constantemente de uma forma a outra, sem se perder nesse movimento, e, com isso, transfor- 


\title{
temporolis
}

\begin{abstract}
ma-se no sujeito automático do processo. Ora, se tomarmos as formas particulares de manifestação que o valor que se autovaloriza assume sucessivamente no decorrer de sua vida, chegaremos a estas duas proposições: capital é dinheiro, capital é mercadoria. Na verdade, porém, o valor se torna, aqui, o sujeito de um processo em que ele, por debaixo de sua constante variação de forma, aparecendo ora como dinheiro, ora como mercadoria, altera sua própria grandeza e, como mais-valor, repele a si mesmo como valor originário valoriza a si mesmo. Pois o movimento em que ele adiciona mais-valor é seu próprio movimento; sua valorização é, portanto, autovalorização. (MARX, 2013, p. 229-30).
\end{abstract}

Em sua exposição da categoria capital, Marx busca edificar a crítica radical à sociedade burguesa, uma forma histórica que determina que sua relação social básica se torne objetivada na forma do mais-valor. Desta forma, podemos compreender que o movimento de autonomização do valor na circulação do dinheiro como capital revela também o movimento de autonomização da mercadoria capaz de gerar mais-valor, o trabalho. Portanto, o dinheiro como meio de pagamento compra a mercadoria força de trabalho e através do processo temporal de consumo desta mercadoria gera-se o mais-valor. As múltiplas formas de trabalhos individuais, separadas no tempo e no espaço, configuram o elã vital de uma abstração social maior (o capital) que engole indivíduos, maquinarias, tecnologias, arte, tempo, etc. e os direciona coercitivamente pela finalidade da produção pela produção - gerar dinheiro para se gerar mais dinheiro.

\section{Considerações Finais}

Com base nos desdobramentos explorados em nosso trabalho, vemos que, com o capital, inaugura-se uma nova forma histórica; sua formação social marca uma suspensão qualitativa de suas relações sociais constituintes à medida que se estrutura a partir de relações de dependência "coisal" onde a própria relação de interação entre o homem e a natureza se torna fechada em atividades instrumentalizadas que adquirem a forma de mercadoria. Esta suspensão qualitativa de relações sociais formalmente determinadas não se restringe ao mundo do trabalho, mas, pelo contrário, se expande e se infiltra por todo conjunto da vida social deixando seus rastros e escombros. 


\section{temporolis}

Por fim, nosso trabalho buscou lançar alguns singelos aportes para ampliar as possibilidades de se repensar a crítica da economia política de Marx. Deixamos apenas algumas sinalizações conclusivas que abarquem pretensões críticas direcionadas a construção de alternativas concretas de transformação societária radical. Reiteramos que aqui se encontra materializado apenas alguns aportes que visam nutrir hipóteses de trabalho, hipóteses comprometidas com o esforço crítico de pensar este "novo tempo do mundo" e as alternativas possíveis de sua supressão histórica.

\section{REFERÊNCIAS}

MARX, K. Contribuição à crítica da economia política. São Paulo: Expressão Popular, 2008.

. O capital: crítica da economia política. São Paulo: Boitempo, 2013.

. Grundrisse. São Paulo: Boitempo, 2011. 


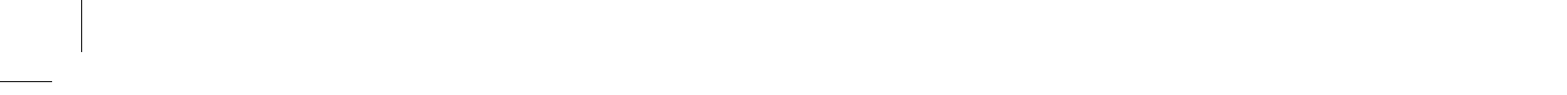

